\title{
Fresh and hardened properties of self-compacting concrete with different mineral additions and fibers
}

\author{
Haddadou N ${ }^{1}$, Chaid R², Ghernouti $\mathrm{Y}^{2,}{ }^{*}$, Adjou N${ }^{1}$ and Bouzoualegh $\mathrm{M}^{1}$
}

1 National Center of Studies and Integrated Research on Building Engineering (CNERIB), Cité Nouvelle ElMokrani, Souidania, Algiers, Algeria.

2 Research Unit: Materials, Processes and Environment (UR/MPE), University of Boumerdes, Cité Frantz Fanon, Boumerdes, Algeria.

* Corresponding Author:y ghernouti@yahoo.fr

\begin{abstract}
In this work, several reinforced self-compacting concretes were prepared by using three types of fibers made of steel, polypropylene and glass, and three different types of mineral additions (marble powder, metakaolin and limestone powder). The water to cement ratio was kept constant at 0.34 and fibers were used in combination, keeping the total fiber content constant at $60 \mathrm{~kg} / \mathrm{m} 3$. Slump flow diameter, L-Box, stability and air content were performed to assess the fresh properties of the concrete. Compressive strength, flexural strength, splitting tensile strength and ultrasonic pulse velocity of the concrete were determined for the hardened properties.

Noteworthy performances were generally obtained, particularly in hardened properties for the self-compacting concretes prepared with steel fibers in association with polypropylene fiber and marble powder as mineral addition.
\end{abstract}

Key words: Self-compacting concrete, Mineral additions, Workability, Fibers, Hardened properties.

\section{Introduction}

Self-compacting concrete (SCC) was developed in Japan in the late 1980's. It is a new concrete which is fully compacted without external energy. SCC has economic, social and environmental benefits over conventionally vibrated concrete. SCC is made from the same basic constituents as conventional concrete but with the addition of high levels of superplasticizer admixtures and occasionally a viscosity modifying admixture to impart high workability. The cement (powder) content of SCC is relatively high and the ratio of fine to coarse aggregates is more important than traditional concretes. Fine fillers such as fly ash, silica fume, slag, metakaolin and marble powder may be used in addition to cement to increase the paste content.

But, one of the disadvantages of SCC is the cost, associated with the usage of chemical admixtures and the high volume of Portland cement. One alternative to reduce the cost of SCC is the usage of mineral additions which are finely divided materials added to concrete as separate ingredients either before or during mixing (Moriconi and Corinaldesi, 2005). The compactness of the SCC matrix, due to the higher amount of fine and extra-fine particles, may improve interface zone properties (Ding, 2010; 2011).

Nowadays, the ecological trend aims at limiting the use of natural raw materials in the field of building materials and hence there is an increased interest in the use of alternative materials (waste) from various industrial activities, which presents significant advantages in economic, energetic and environmental terms.

The objective of this study is to assess the effects of mineral additions replacement on the fresh and hardened properties of SCCs incorporating different fibers in combination. Marble powder (MP) has been used as an important building material for centuries, especially for decorative purposes. During sawing, shaping, and polishing process, $25 \%$ of the processed marble turned into dust or powder form (Alyamaç and Ince, 2009).The use of MP in the concrete had not found adequate attention. Corinaldesi et al. (2010) stated that since its high degree of fineness, MP was proved to be very effective in providing very good cohesiveness of mortar and concrete. Even 
though, the suitability of using such sub-standard MP in fiber-reinforced self-compacting concrete needs much detailed investigation. Metakaolin (MK) is a pozzolanic material, obtained by dehydroxylation of kaolin (Lamberov, 2012). In recent years MK was applied as mineral addition for preparation of SCC. MK leads to improved mechanical properties and durability of the concrete. The particle size of MK is much fine than cement and prevent, the aggregation. Furthermore, SCC with participation of MP showed enhanced viscosity and workability (Cassagnabère, 2013; Rashad, 2013).

Limestone powder (LP) is widely applied for preparation of SCC. When high volumes of LP are added to SCC mixture, the required self-compacting properties are achieved at a lower water/binder ratio. The strength after 28 days is also increased, due to filler effect resulting in improved fine-particle packing with LP particles. Partial substitution of cement with LP, leads to increasing slump flow, viscosity, and compressive strength at early ages. Also LP reduces, the amount of used cement, which respectively influence at the price of prepared concrete (Uysal and Yilmaz, 2011; Topcu, 2009).

This paper covers some fresh and hardened properties of such mixtures. In addition to the MP, MK and LP are used; three different fibers were used in different proportions in making the concrete. The total mass of cementitious materials is $500 \mathrm{~kg} / \mathrm{m} 3$, where $30 \%$ of cement is replaced by mineral addition. For comparison, a control SCC mixture without fibers was also produced. The commercially available chemical admixtures used in this study included a viscosity modifying admixture (VMA) and Polycarboxylic based superplasticizer (SP).

\section{Experimental procedure}

\subsection{Materials}

A 42.5 CEM II/A cement from M'sila factory is the type of binder used for making concretes for the purpose of the work undertaken and metakaolin (MK), limestone powder (LP) and marble powder (MP) were used as cementitious materials in the mix proportions. The chemical properties of cement, MK, LP and MP are given in Table 1 whereas the mineralogical composition of cement is given in Table 2. Workability improvement of SCCs was obtained thanks to the polycarboxylate superplasticizer (SP) MEDAFLOW 145 and the viscosity modifying admixture (VMA) Medacol BSE. The properties of both admixtures, as provided by their manufactures, are shown in Table 3 . Continuously graded coarse aggregates (3/8 and 8/15) were used with specific gravity and water absorption of $2.56 \mathrm{~g} / \mathrm{cm}^{3}$ and $1.03 \%$ respectively. Natural dune sand (DS) and river sand (RS) were used. Selected sands are subjected to grain size distribution analysis as per XP P 18-540 standard (1997). The set of sieves are taken from 5mm to $0.063 \mathrm{~mm}$ with aggregate and sieve shaker subjected to vibration for 15 minutes. Physical properties of used sands are given in Table 4. The gradation of coarse and fine aggregates was determined by sieve analysis and presented in Figure 1. Different types of fibers were used, polypropylene fibers (P), steel fibers $(\mathrm{S})$ and glass fibers $(\mathrm{G})$ (Figure 2). Tap water was used to produce all mixtures.

Table 1. Chemical properties of binders.

\begin{tabular}{ccccc}
\hline Element $(\%)$ & Cement & MP & MK & LP \\
\hline \hline $\mathrm{SiO}_{2}$ & 16.80 & 0.48 & 73.60 & 0.7 \\
$\mathrm{Al}_{2} \mathrm{O}_{3}$ & 4.46 & 0.10 & 16.36 & 0.15 \\
$\mathrm{Fe}_{2} \mathrm{O}_{3}$ & 2.94 & 0.12 & 1.07 & 0.09 \\
$\mathrm{CaO}$ & 58.83 & 54.54 & 0.39 & 54.42 \\
$\mathrm{MgO}$ & 1.68 & 0.72 & 0.16 & 1.22 \\
$\mathrm{SO}_{3}$ & 2.35 & 0.46 & 0.01 & 0.01 \\
$\mathrm{~K}_{2} \mathrm{O}_{2}$ & 0.60 & 0.01 & 4.56 & 0.01 \\
$\mathrm{Na}_{2} \mathrm{O}$ & 0.03 & 0.01 & 3.22 & 0.13 \\
$\mathrm{P}_{2} \mathrm{O}_{5}$ & 0.15 & 0.02 & 0.13 & 0.01 \\
$\mathrm{TiO}_{2}$ & 0.22 & 0.01 & 0.08 & 0.01 \\
Loss of ignition & 11.74 & 43.53 & 0.43 & 43.24 \\
\hline
\end{tabular}


Table 2. Mineralogical composition of cement.

\begin{tabular}{cc}
\hline Element & $(\%)$ \\
\hline \hline $\mathrm{C}_{3} \mathrm{~S}$ & 56 \\
$\mathrm{C}_{2} \mathrm{~S}$ & 20 \\
$\mathrm{C}_{3} \mathrm{~A}$ & 5 \\
$\mathrm{C}_{4} \mathrm{AF}$ & 13 \\
\hline
\end{tabular}

Table 3. Properties of chemical admixture.

\begin{tabular}{cccccc}
\hline $\begin{array}{c}\text { Chemical } \\
\text { admixture }\end{array}$ & $\begin{array}{c}\text { Specific } \\
\text { gravity }\end{array}$ & $\mathrm{pH}$ & Color & $\begin{array}{c}\text { Recommended } \\
\text { dosage }\left(\mathrm{l} / \mathrm{m}^{3}\right)\end{array}$ & Main component \\
\hline \hline SP & 1.06 & 5.5 & Light brown & 0.3 to 2 & $\begin{array}{c}\text { Carboxylic ether } \\
\text { Aqueous dispersion of } \\
\text { microscopic silica }\end{array}$ \\
\hline
\end{tabular}

Table 4. Properties of sands.

\begin{tabular}{ccc}
\hline Properties & DS & RS \\
\hline \hline Fineness modulus & 1.29 & 2.85 \\
Sand equivalent (\%) & 48 & 90 \\
Absorption (\%) & 2.43 & 0.63 \\
Moisture content (\%) & 1 & 0.42 \\
\hline
\end{tabular}

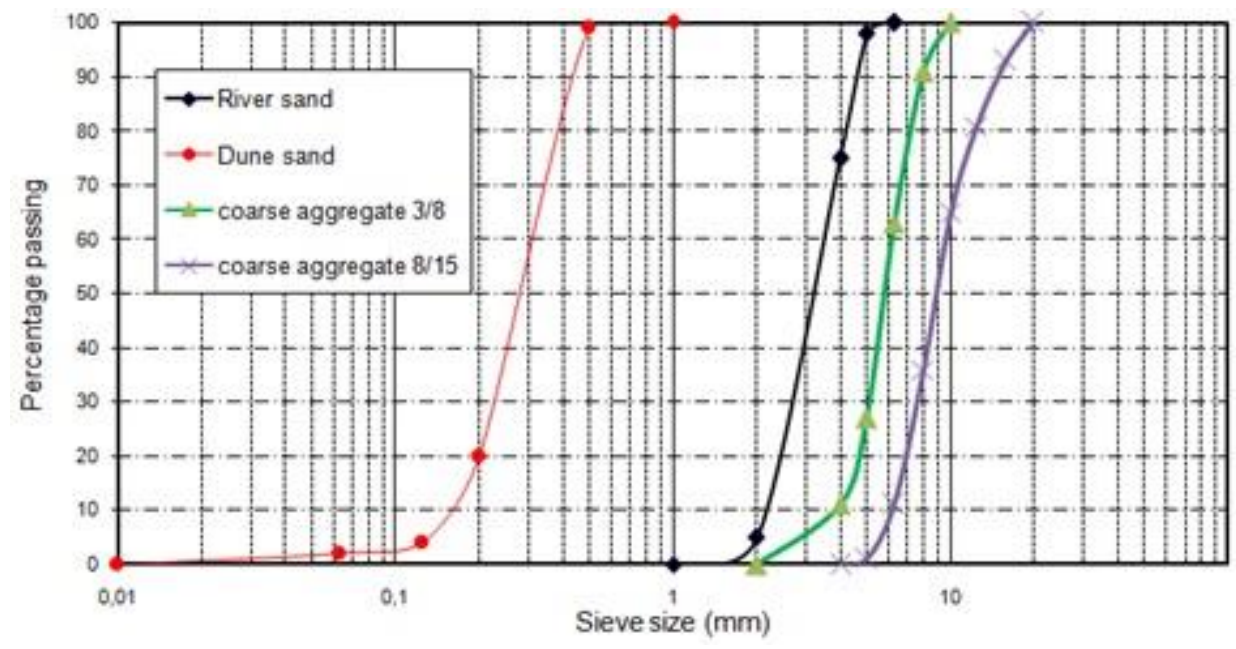

Fig 1. Particle size distribution of coarse and fine aggregates.

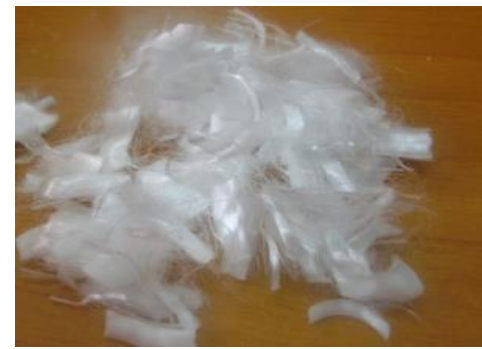

a)

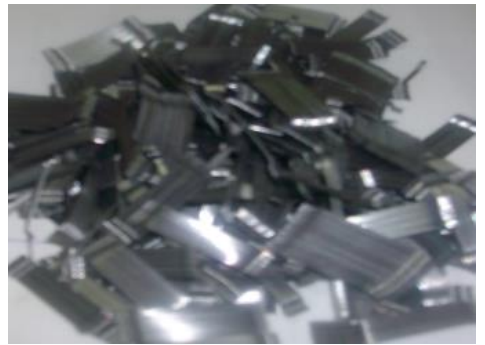

b)

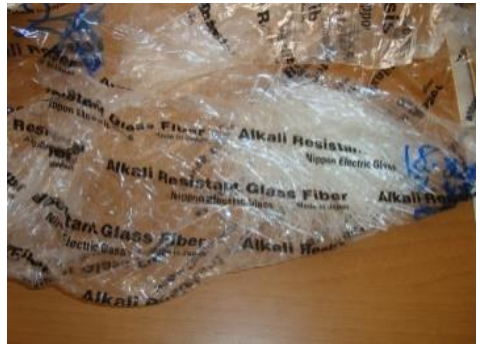

c)

Fig 2. Fibers used for the production of RSCC: a) polypropylene (P), b) steel (S) and c) glass (G).

\subsection{Mixture proportions}

Numbers of attempts were made in laboratory to get optimum mix proportion to produce SCC without segregation and bleeding with satisfying the properties both in fresh and hardened states. For this study totally twelve SCC mixes were prepared with a constant water to binder ratio of 0.34 and with $1.7 \%$ of superplasticiser. Four types of mixes were prepared with different binder contents, without fibers (SCC) and with different type of fiber reinforcement (RSCC). The 
prepared mixes were designated as, SCC (SCC30\%MP, SCC30\%MK, SCC30\%LP), RSCCI $(30 \% \mathrm{MP}+60 \mathrm{~kg}$ of steel fiber, $30 \% \mathrm{MP}+60 \mathrm{~kg}$ of steel fiber+ polypropylene, $30 \% \mathrm{MP}+60 \mathrm{~kg}$ of steel fiber+ glass fiber ), RSCCII $(30 \% \mathrm{MK}+60 \mathrm{~kg}$ of steel fiber, $30 \% \mathrm{MK}+60 \mathrm{~kg}$ of steel fiber+ polypropylene, $30 \% \mathrm{MK}+60 \mathrm{~kg}$ of steel fiber+ glass fiber ) and RSCCIII $(30 \% \mathrm{LP}+60 \mathrm{~kg}$ of steel fiber, $30 \% \mathrm{LP}+60 \mathrm{~kg}$ of steel fiber+ polypropylene, $30 \% \mathrm{LP}+60 \mathrm{~kg}$ of steel fiber+ glass fiber ).The mix proportions are presented in Table 5.

The SCC was mixed for 5 minutes in laboratory drum mixer. For all mixes, nine cube specimens of $150 \mathrm{~mm}$ size were cast from each mix for compressive strength testing. Six cylindrical specimens of $150 \mathrm{~mm}$ diameter and $300 \mathrm{~mm}$ height were also cast from each mix for determining the splitting tensile strength. Before compression test, all specimens were tried and used for ultrasonic pulse velocity test. Six prisms of $70 * 70 * 280 \mathrm{~mm}$ were cast from each mix for flexural strength. After casting, all the specimens were left covered in the casting room for 24 hours. The specimens were demoulded and transferred to moist curing room until the time of testing.

Table 5. Mix proportions.

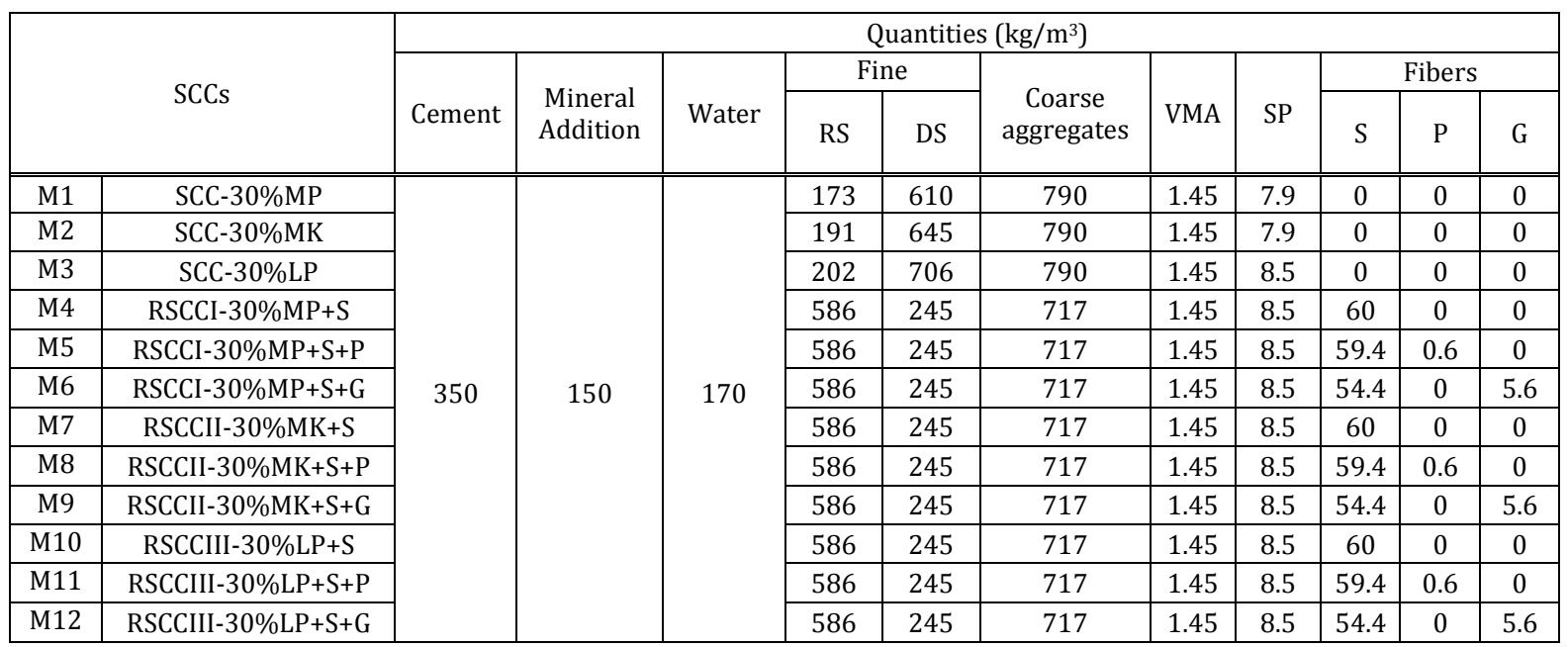

\subsubsection{Preparation and casting of test specimens}

The mixing procedure and time are very important, thus the mixing process was kept constant for all concrete mixtures. The following mixing sequence was obtained after several trials for optimizing the workability. All the ingredients were first mixed under dry condition in the concrete mixer for one minute. Then $70 \%$ of calculating amount of water was added to the dry mix and mixed thoroughly for one minute. The remaining $30 \%$ of water was mixed with the SP and VMA and was poured into the mixer and mixed for five minutes (four minutes for $20 \%$ of the remaining water with SP and one minute for $10 \%$ of remaining water with the VMA). Later, required quantities of fibers were sprinkled over the concrete mix and mixed for one minute to get a uniform mix. Thus, the total mixing time was 7 minutes. In this investigation, fresh properties were evaluated by the flowability (slump flow diameter), passing ability (L-Box), air content and stability (sieve stability test) (EFNARC, 2005), as represented in Figure 3.

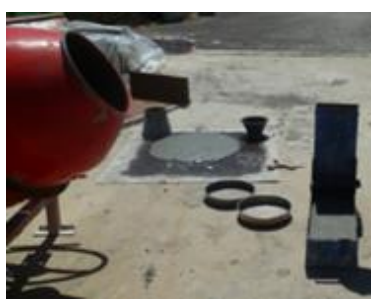

Workability tests

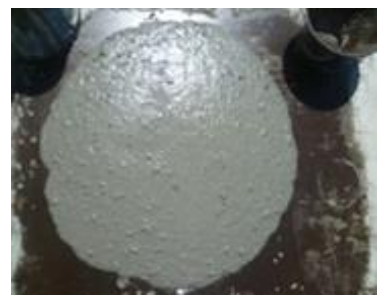

Slump flow test

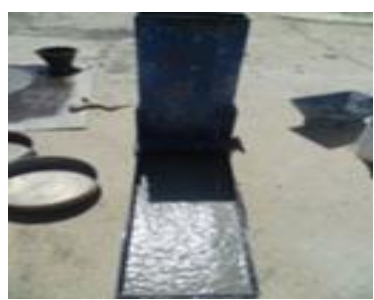

L-Box test

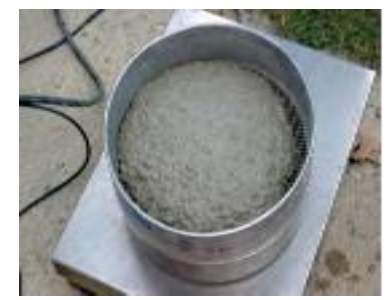

Sieve stability test

Fig 3. Fresh properties tests. 


\subsubsection{Test on hardened concrete}

Concrete specimens have been batched, moulded and cured according to AFNOR standard (EN $12390-2,2001)$. All the moulds were covered by plastic sheets and stored for 24 hours in the laboratory prior to demoulding; afterwards, they were cured in water at $20^{\circ} \mathrm{C}$ and at relative humidity (RH) in the order of $50-60 \%$.

A testing programme has been elaborated and consisted of determining the essential properties of hardened self-compacting concretes.

The necessary test specimens have been cast in different moulds and three tests were carried out to assess each required characteristic. For the determination of compressive strength and ultrasonic pulse velocity concrete cubes of $150 * 150 * 150 \mathrm{~mm}^{3}$ were used (EN 12390-3, 2001; EN 12504-4, 2005). Compressive strength was measured at 7, 28 and 56 days old using a testing machine with a maximum load capacity of $3000 \mathrm{kN}$. The splitting tensile strength and flexural strength was measured on $150 * 300 \mathrm{~mm}^{3}$ cylindrical and $70 * 70 * 280 \mathrm{~mm}^{3}$ specimens at 28 and 56 days, using a testing machine with a maximum load capacity of $100 \mathrm{kN}$. The average of three specimen properties at a particular age was considered as its property.

\section{Results and Discussion}

\subsection{Fresh concrete properties}

To classify a concrete as self-compacting, the requirements for filling and passing abilities as well as segregation resistance must be fulfilled in order to provide ease of flow in the presence of formwork or reinforcement and an ability to remain homogeneous in fresh state. It is specified that the filling ability and stability of SCC in the fresh state can be defined by four key characteristics namely flowability, viscosity, passing ability, and segregation resistance (Barr, 1996). Fresh properties of the concretes were carried out according to the limitations specified by EFNARC (2005).

The results obtained of fresh properties are reported in Table 6. As seen from this table, the fresh properties are in the range of $65.5-77 \mathrm{~cm}$ for the slump flow, $0.80-0.89$ for the L-box ratio, $1.90-2.85 \%$ for air content of and $3.72-6.85 \%$ for the sieve stability. All concrete mixtures were considered as SCC. In all SCC mixtures, there was no segregation of aggregate near the edges of the spread-out concrete as observed from the slump flow test.

Table 6. Fresh properties of self-compacting concretes.

\begin{tabular}{cccccc}
\hline Mix N & Mix ID & $\begin{array}{c}\text { Slump flow } \\
(\mathrm{cm})\end{array}$ & $\begin{array}{c}\text { Air content } \\
(\%)\end{array}$ & $\begin{array}{c}\text { L-Box ratio } \\
(\%)\end{array}$ & $\begin{array}{c}\text { Sieve stability } \\
(\%)\end{array}$ \\
\hline \hline M1 & SCC-30\%MP & 75 & 02.00 & 0.89 & 05.59 \\
M2 & SCC-30\%MK & 68 & 01.90 & 0.84 & 06.65 \\
M3 & SCC-30\%LP & 77 & 02.15 & 0.88 & 06.32 \\
M4 & RSCCI-30\%MP+S & 70.5 & 02.70 & 0.80 & 04.13 \\
M5 & RSCCI-30\%MP+S+P & 73 & 02.60 & 0.83 & 04.96 \\
M6 & RSCCI-30\%MP+S+G & 70 & 02.60 & 0.81 & 04.47 \\
M7 & RSCCII-30\%MK+S & 65.5 & 02.14 & 0.79 & 03.85 \\
M8 & RSCCII-30\%MK+S+P & 68.5 & 02.54 & 0.80 & 03.72 \\
M9 & RSCCII-30\%MK+S+G & 69 & 02.85 & 0.80 & 03.87 \\
M10 & RSCCIII-30\%LP+S & 72 & 02.80 & 0.84 & 06.76 \\
M11 & RSCCIII-30\%LP+S+P & 69 & 02.23 & 0.81 & 06.01 \\
M12 & RSCCIII-30\%LP+S+G & 67 & 02.60 & 0.83 & 06.85 \\
\hline
\end{tabular}

The comparison between SCC, RSCCI, RSCCII and RSCCII a replacement of cement by MP have shown good slump values, therefore MP can be considered as limestone filler which is one of the materials that have extensively been studied in the literature (Elkhadiri, 2002; Petit and Wirquin, 2010) and have improved the performances of concretes by providing more compact structure through its pore-filling effect. MP helps to evenly disperse aggregates during mixing 
but it needs more superplasticizer to improve a good flowability. Although the angular shapes with rough surface texture of MP particle, it provide ball bearing effects and reduce internal friction in fresh concrete and these increase the flowability and compaction of the concrete. In other hand, using of MK has slightly affect workability measures in comparison with MP and LP.

The fiber-matrix adhesion as well as geometry of the fiber affects pullout behavior of the fibers. MP, MK and LP help to evenly disperse fibers during mixing. MP and LP particles provide ball bearing effects and reduce internal friction in fresh concrete and these increase the flowability and compaction of the concrete.

The fibers have also affected the fresh properties of the concrete mixtures. For the same workability, the addition of polypropylene and glass fibers did not affect the water requirement of RSCC mixture with steel fibers.

\subsection{Hardened concrete properties}

To evaluate the effect of mineral additions and fibers on the hardened properties of studied SCC mixtures, different tests are conducted (Figure 4). The hardened concrete test results are presented in Figures 5, 6, 7 and 8 which included the 7, 28 and 56 days for compressive strength, 28 and 56 days for flexural and splitting strength and ultrasonic pulse velocity at 56 days.

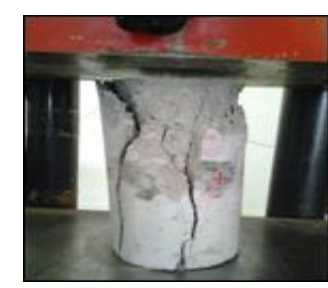

Compressive strength

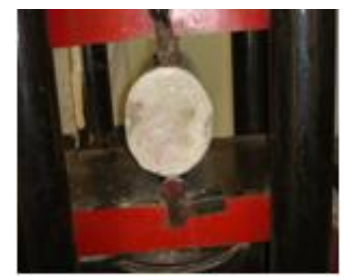

Split tensile strength

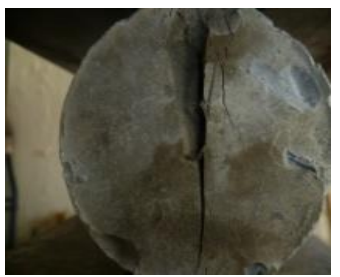

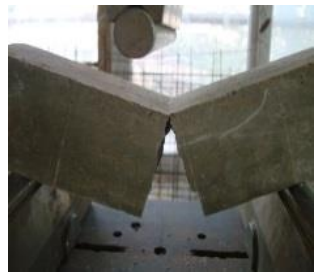

Flexural strength
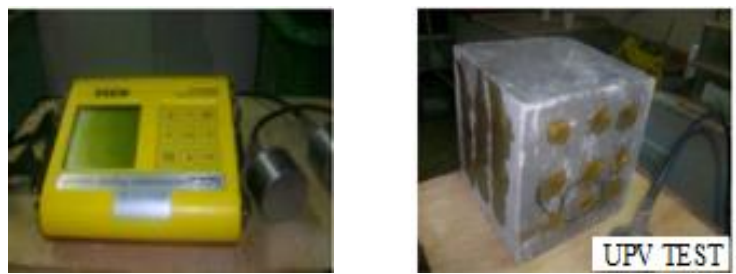

Ultrasonic pulse velocity (UPV)

Fig 4. Hardened properties tests.

As seen from the obtained results, the most significant changes were observed respectively on the flexural strength, splitting tensile strength, compressive strength and lastly on the ultrasonic pulse velocities.

Compressive strengths of various concrete mixtures are given Figure 5. The compressive strengths of SCCs and RSCCs were in the range of 22.68- $39.78 \mathrm{MPa}$ from 7 days to 56 days. The binary use of cement with mineral addition increases the compressive strength of RSCCs. However, replacement of cement with $30 \%$ of MP caused a reduction about $5 \%$ in the compressive strength comparing to MK.

Conversely, this adverse effect of MP seemed to be remedied by the combined use of the mineral additions. Interestingly, the concrete containing 30\% MK achieved the highest compressive strength of all mixtures. Therefore, the test results suggested that it was the MP, among the mineral additions used that governed the reduction in the compressive strength of the SCCs mixtures. 


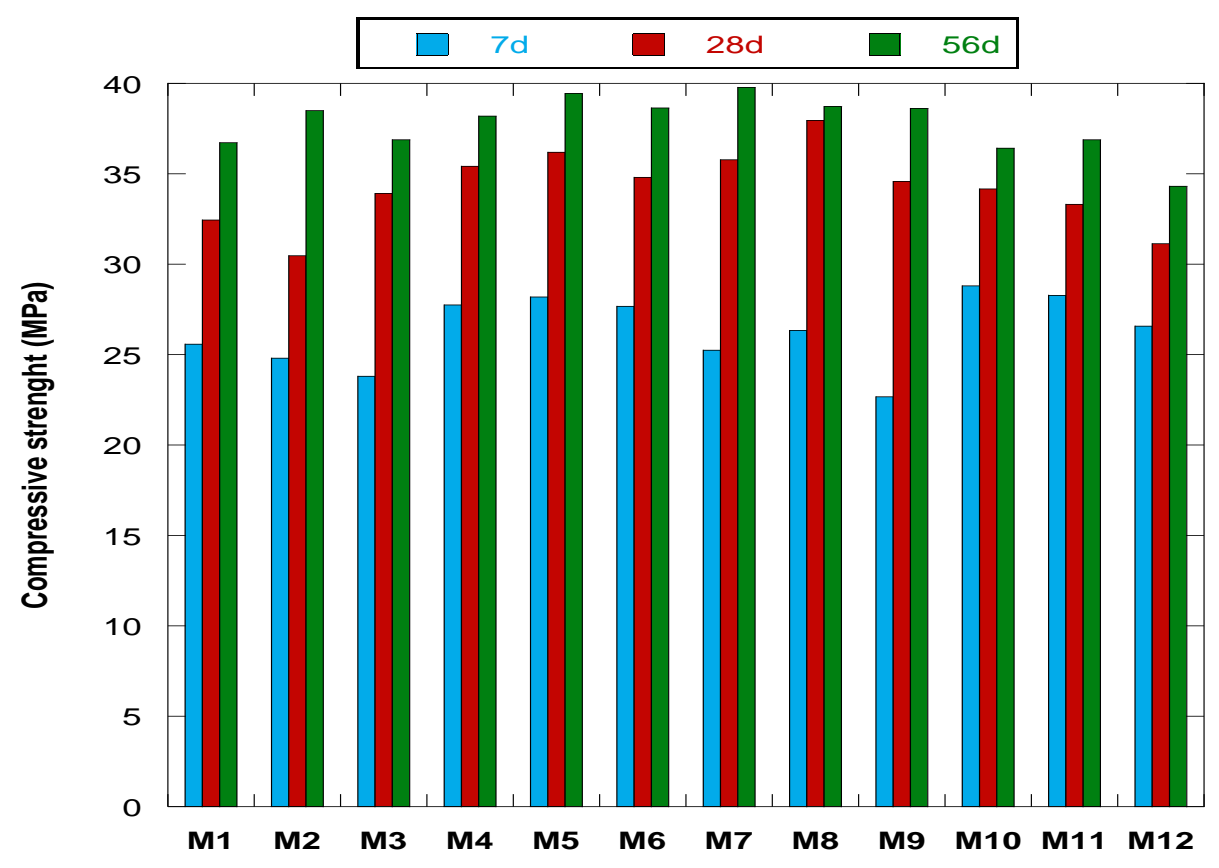

Fig 5. Compressive strength of SCCs.

Results obtained for flexural strength (Figure 6) showed the effectiveness of mineral additions in improving the flexural behavior of concrete (enhanced also by the presence of fibers).

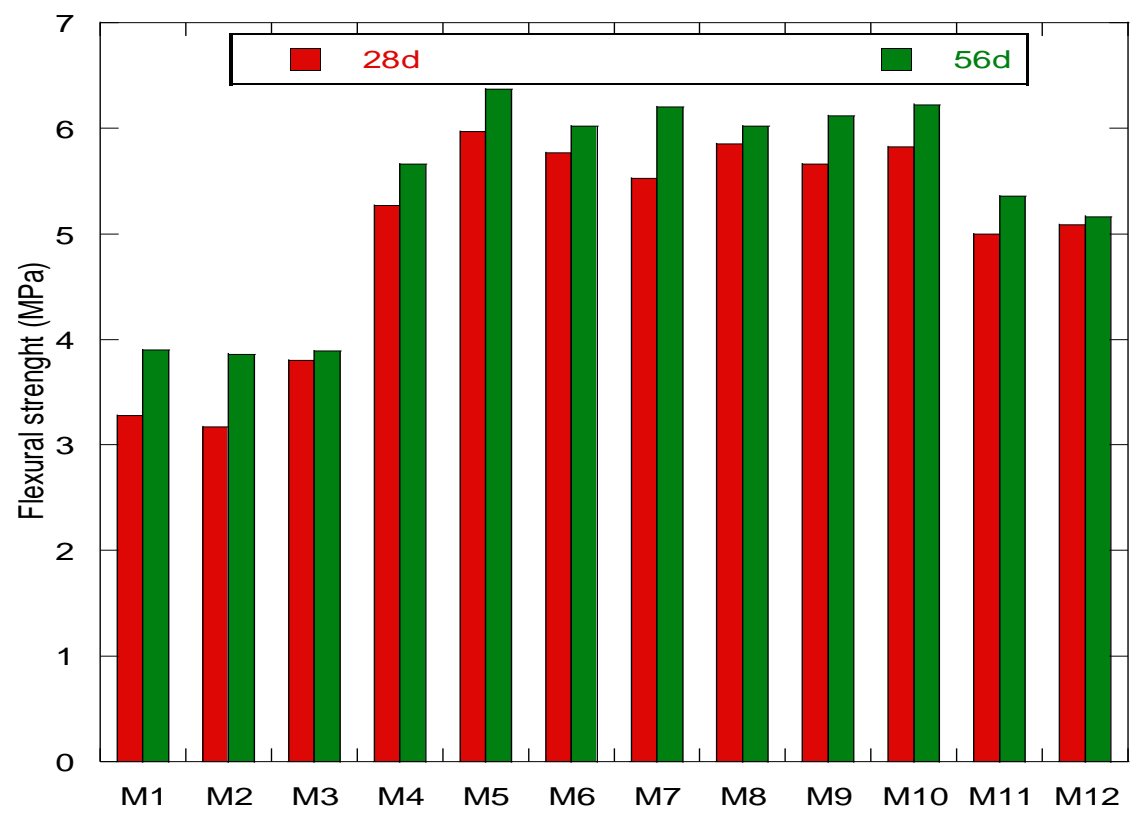

Fig 6. Flexural strength (MPa).

Splitting tensile strength (Figure 7), seemed to be affected by the fibers and the effect of fiber hybridization can be observed on the obtained test results. Highest splitting tensile strength obtained in M8 (polypropylene fiber in combination with steel fiber reinforced concrete) and in M7 (steel fibers reinforced concrete). It can be observed that all mixes containing fibers have splitting tensile strength greater than the control mix. The increasing of tensile strength in mixes containing steel fibers can be attributing to the properties of these fibers which make the concrete less brittle and more ductile.

Ultrasonic pulse velocity (UPV) test results are presented in Figure 8. It can be seen from this figure that the UPV test values did not seem to be affected by the size of fibers in this research. 
However, the UPV test could be used to assess the hardening of the SCC mixtures. It is clear that as hydration continued, the UPVs increased for all the SCCs mixtures.

The values of UPV in this research were ranged from $4235 \mathrm{~m} / \mathrm{s}$ to $4415 \mathrm{~m} / \mathrm{s}$. Similar to the compressive strength, the concrete with $30 \%$ MK had the highest UPV value. Whitehurst (1951) classified the concrete quality according to UPV values as excellent ( $4500 \mathrm{~m} / \mathrm{s}$ and above), good $(3500-4500 \mathrm{~m} / \mathrm{s})$, doubtful $(3000-3500 \mathrm{~m} / \mathrm{s})$, poor $(2000-3000 \mathrm{~m} / \mathrm{s})$ and very poor $(2000$ $\mathrm{m} / \mathrm{s}$ ). The concretes produced in this study have UPV values greater than $3500 \mathrm{~m} / \mathrm{s}$ and lower than 4500 , so that the rating of the concretes was found to be good.

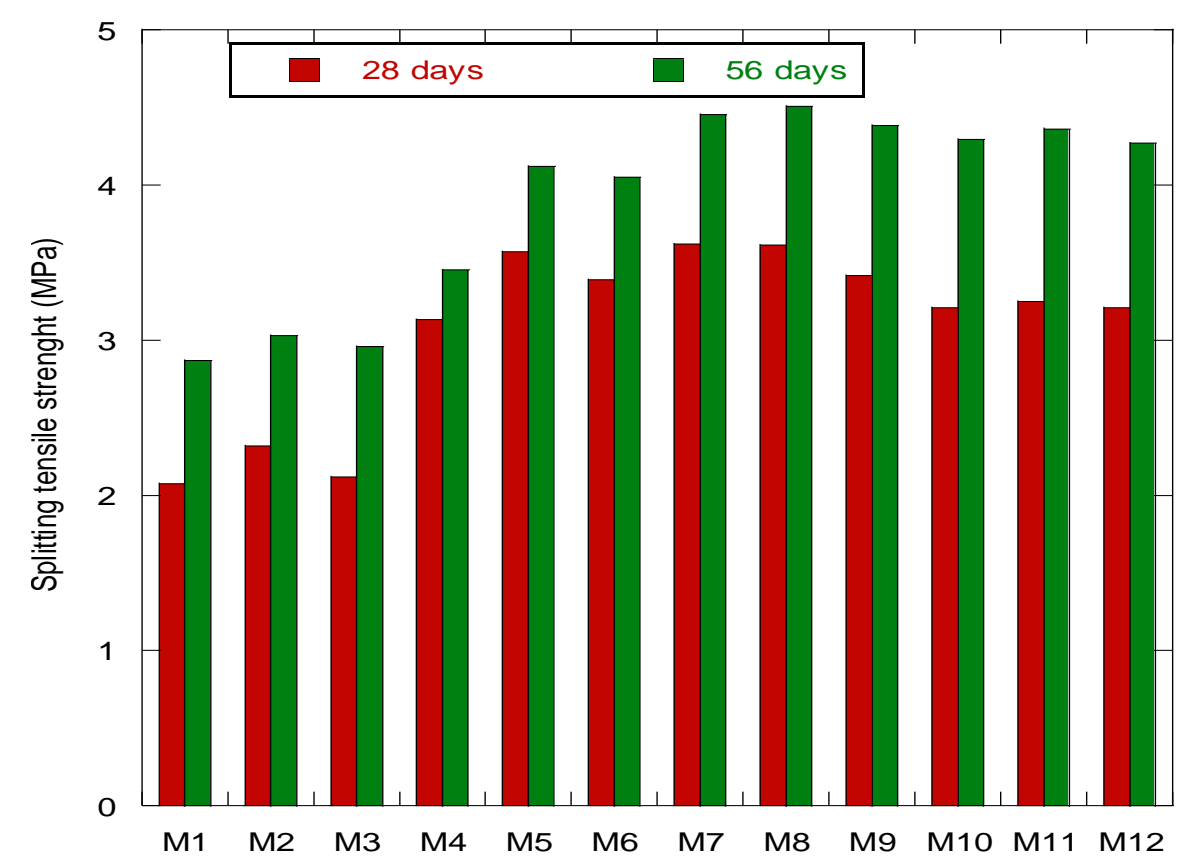

Fig 7. Splitting tensile strength (MPa).

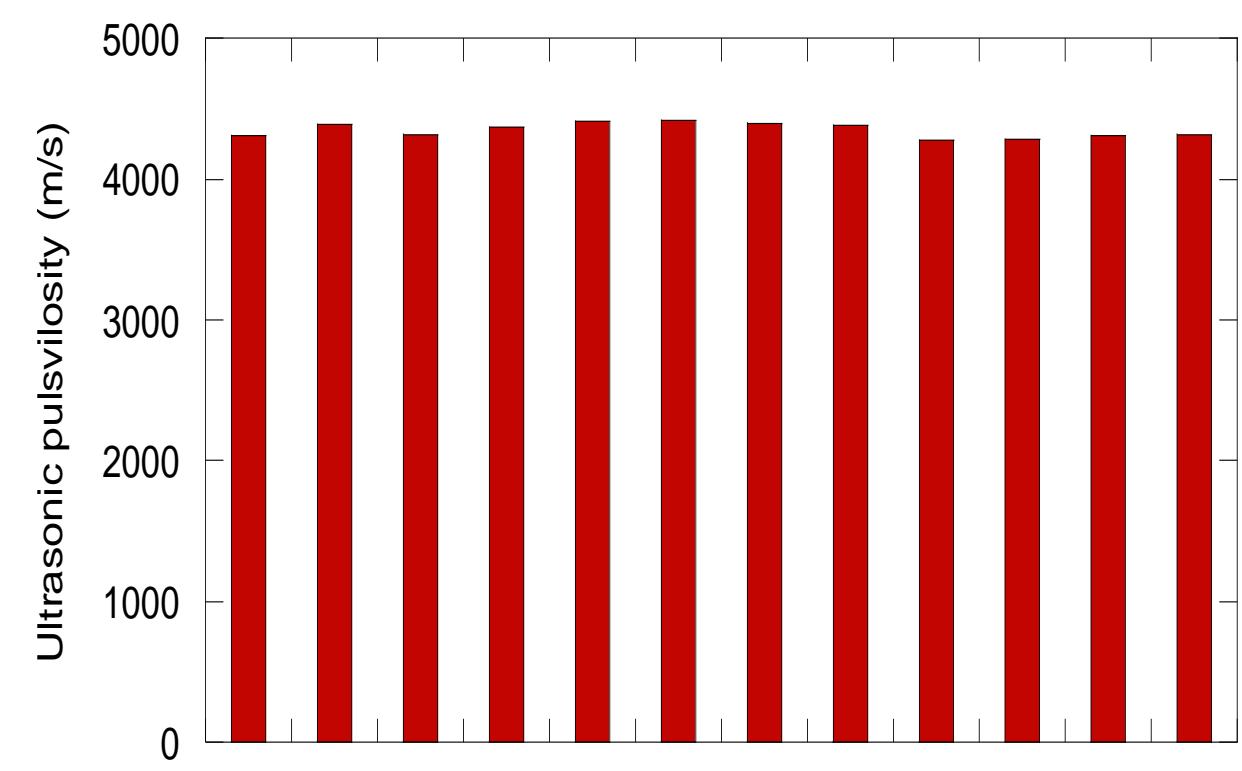

$\begin{array}{llllllllllll}\text { M1 } & \text { M2 } & \text { M3 } & \text { M4 } & \text { M5 } & \text { M6 } & \text { M7 } & \text { M8 } & \text { M9 } & \text { M10 } & \text { M11 } & \text { M12 }\end{array}$

Fig 8. Ultrasonic pulse velocity $(\mathrm{m} / \mathrm{s})$. 


\section{Conclusions}

An experimental programme has been undertaken to investigate the performance of selfcompacting concrete containing marble powder, limestone powder and metakaolin as a partial replacement of cement. Steel, polypropylene and glass fibers are used to produce reinforced selfcompacting concrete. The following conclusions can be drawn from this study:

- It was observed that for all fiber and mineral addition types and mixture proportions tested, there were no problems in mixing and the fiber distribution was uniform.

- All mixtures tested in this study were able to attain $60 \mathrm{~kg} / \mathrm{m}^{3}$ of steel, polypropylene and glass fibers without loss of flow and workability. It is important to note that all of volume fiber fractions used in reinforced mixtures exceeded the upper limits suggested by EFNARC. Although, all mixtures have good flowability and possessed self-compacting characteristics.

- It was found that the flow behavior of hybrid fiber reinforced concrete differs from that of plain self-compacting concrete with $30 \%$ of mineral addition.

- It was found that a considerable amount of hybrid fibers can allowed a good self compactability. In order to retain high level workability with fiber reinforcement, the amount of paste in the mix should be increased to provide better dispersion of fibers.

- It is possible to produce hybrid fiber concretes using polypropylene fibers and glass fibers in combination with steel fibers, with an enhanced strengths compared to controlled concrete without fibers.

- SCC with steel and polypropylene hybrid fiber with metakaolin as mineral addition showed the high mechanical properties over reference concrete (M1, M2, M3) or single fibers and hybrid with glass fiber.

\section{References}

Alyamaç, K. E., \& Ince, R. (2009). A preliminary concrete mix design for SCC with marble powders. Construction and Building Materials, 23(3), 1201-1210.

Barr, B., Gettu, R., Al-Oraimi, S. K. A., \& Bryars, L. S. (1996). Toughness measurement-the need to think again. Cement and Concrete Composites, 18(4), 281-297.

Cassagnabère, F., Diederich, P., Mouret, M., Escadeillas, G., \& Lachemi, M. (2013). Impact of metakaolin characteristics on the rheological properties of mortar in the fresh state. Cement and Concrete Composites, 37, 95-107.

Corinaldesi, V., Moriconi, G., \& Naik, T. R. (2010). Characterization of marble powder for its use in mortar and concrete. Construction and Building Materials, 24(1), 113-117.

Ding, Y., You, Z., \& Jalali, S. (2010). Hybrid fiber influence on strength and toughness of RC beams. Composite Structures, 92(9), 2083-2089.

Ding, Y., You, Z., \& Jalali, S. (2011). The composite effect of steel fibres and stirrups on the shear behaviour of beams using self-consolidating concrete. Engineering Structures, 33(1), 107-117.

EFNARC (2005). European guidelines for self-compacting concrete: Specification, production and use. Selfcompacting concrete, European Project Group.

Elkhadiri, I., Diouri, A., Boukhari, A., Aride, J., \& Puertas, F. (2002). Mechanical behaviour of various mortars made by combined fly ash and limestone in Moroccan Portland cement. Cement and Concrete Research, 32(10), 1597-1603.

EN 12390-2 (2001). Testing hardened concrete - Part 2: Making and curing specimens for strength tests.

EN 12390-3 (2001). Testing hardened concrete - Part 3: Compressive strength of test specimens.

EN 12504-4 (2005). Testing hardened concrete - Part 4: Ultrasonic pulse velocity of test specimens. 
Lamberov, A. A., Sitnikova, E. Y., \& Abdulganeeva, A. S. (2012). Kinetic features of phase transformation of kaolinite into metakaolinite for kaolin clays from different deposits. Russian Journal of Applied Chemistry, 85(6), 892-897.

Moriconi, G., \& Corinaldesi, V. (2005). Rheological study of blended cement concrete. In proceeding: Cement Combinations for Durable Concrete, edited by Dhir RK. Harrison TA., Newlands MD. In The 6th Int. Congress on "Global Construction: Ultimate Concrete Opportunities". Thomas Telford, London, UK, pp. 211-218.

Petit, J. Y., \& Wirquin, E. (2010). Effect of limestone filler content and superplasticizer dosage on rheological parameters of highly flowable mortar under light pressure conditions. Cement and Concrete Research, 40(2), 235-241.

Rashad, A. M. (2013). Metakaolin as cementitious material: History, scours, production and composition-A comprehensive overview. Construction and building materials, 41, 303-318.

Topcu, I. B., Bilir, T., \& Uygunoğlu, T. (2009). Effect of waste marble dust content as filler on properties of self-compacting concrete. Construction and Building Materials, 23(5), 1947-1953.

Uysal, M., \& Yilmaz, K. (2011). Effect of mineral admixtures on properties of self-compacting concrete. Cement and Concrete Composites, 33(7), 771-776.

Whitehurst, E. A. (1951). Soniscope tests concrete structures. In Journal Proceedings of American Concrete Institute, 47(2), 433-444.

XP P 18-540 Standard (1997). Granulats: Définitions, conformité, spécifications, Association Française de Normalisation, Paris, (In french). 